\title{
Systematic Modification of Indium Tin Oxide to Enhance Diode Device Behavior
}

\author{
Jing Guo, ${ }^{\dagger}$ Norbert Koch, ${ }^{\ddagger}$ Jeffrey Schwartz, ${ }^{\dagger}$ and Steven L. Bernasek ${ }^{\dagger}$ \\ ${ }^{\dagger}$ Department of Chemistry, Princeton University, Princeton, NJ 08544-1009 \\ ‡Institut für Physik, Humboldt-Universität zu Berlin, D-12489 Berlin, Germany
}

\begin{abstract}
Monolayers of tin complexes of phenoxide ligands spanning a range of dipole moments were prepared on the surface of ITO via simple metathesis reactions. They were characterized by quartz crystal microgravimetry (QCM) and a Kelvin probe. A nearly linear relationship was found between the measured ITO work functions and dipoles of the surface complexes. Measurements of current densities of diode devices built on surface modified ITO anodes were made, and a correlation was found between the total surface dipole per unit area and these current densities. Simple OLED devices were also constructed using these modified anodes.
\end{abstract}

\section{INTRODUCTION}

Surface modification of ITO has received wide attention as a means to control its anode properties, particularly to increase its work function in order to lower the barrier to hole injection in novel organic-based optoelectronic devices [1-6]. A simple electrostatic model has been proposed [7] within this context as a guide to enable this increase in work function. This model is based on an introduced dipole layer on the surface of the ITO [8,9]: The effected work function change $(\Delta \phi)$ should be directly proportional to the normal component of molecular dipole moments of surface-attached species $\left(\mu_{\mathrm{z}}\right)$ and to the number of such species, per unit area, on the surface.

Using organics to effect work function changes for ITO according to the "dipole model" has been described qualitatively, but no quantitative conformity to the "dipole model" had been established. We described surface modification of ITO in ultrahigh vacuum using a series of tin phenoxides [10,11], and we showed that a correlation existed between dipole moments of the parent phenols and changes in the ITO work function that occurred on formation of the surface complexes [11]. Surface loadings were not known. We have reported that the surface deposition and ligand metathetical reactions for tin alkoxides on ITO recorded in UHV $[10,11]$ can be accomplished under normal laboratory conditions (see scheme 1). We found that performing these deposition and metathesis reactions on an ITO electrode-equipped quartz crystal microbalance (QCM) gives us surface complex loadings which, together with Kelvin probe vibrating capacitor measurements of the ITO work function, enabled calculation of surface complex dipole moments to be made and to be related to the "dipole model" [12]. The current density results of ITO treated with such modifications further reveal the quantitative 
control of device performance based on electrostatic theory. OLEDs based on these modified electrodes have now also been prepared and studied.

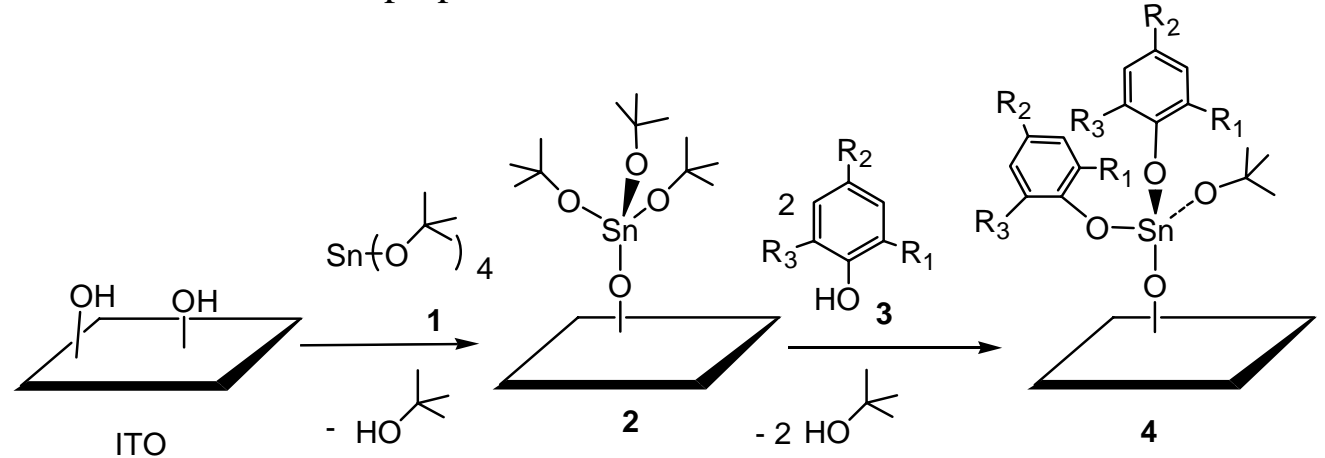

Scheme 1. Synthesis of Surface Tin Phenoxides.

a: $\mathrm{R}_{1}=\mathrm{R}_{3}=\mathrm{R}_{2}=\mathrm{H} ; \mathbf{b}: \mathrm{R}_{1}=\mathrm{R}_{3}=\mathrm{H}, \mathrm{R}_{2}=\mathrm{F} ; \mathbf{c}: \mathrm{R}_{1}=\mathrm{R}_{3}=\mathrm{H}, \mathrm{R}_{2}=\mathrm{CF}_{3} ; \mathbf{d}: \mathrm{R}_{1}=\mathrm{R}_{3}=\mathrm{F}, \mathrm{R}_{2}=\mathrm{H}$

\section{EXPERIMENTAL SECTION}

ITO slides were cleaned using detergents and organic solvents [12], without ozone or plasma treatment [9]. Then they were placed in a vacuum chamber $\left(10^{-3}\right.$ torr $)$ and were exposed to vapor of $\mathbf{1}$. Excess 1 was removed in vacuo, and the treated surfaces were exposed to vapor of 3a-d. Excess phenol was removed in vacuo. A homemade Kelvin probe [12] was used for the measurement of work function changes for the treated ITO. The same gold standard was used for each trial. Loadings of surface complexes and surface complex stoichiometries were determined by quartz crystal microgravimetry (QCM) [12].

ITO glass slides used for device fabrication were polished with silica before cleaning as described above. Deposition of $\alpha-\mathrm{NPD}, \mathrm{Alq}_{3}$ and aluminum was done successively in an Edwards 306A thermal evaporation system at $8 \times 10^{-7}$ mbar. For hole-only devices, $140 \mathrm{~nm}$ of $\alpha$-NPD and $60 \mathrm{~nm}$ of Al were deposited on the ITO substrates. For OLED devices, $60 \mathrm{~nm}$ of $\alpha-$ $\mathrm{NPD}, 60 \mathrm{~nm}$ of $\mathrm{Alq}_{3}$ and $75 \mathrm{~nm}$ of Al were deposited successively on the ITO substrates. Photos of luminescent devices were taken at $15 \mathrm{~V}$ driving voltage with a Nikon Coolpix 950 digital camera.

\section{RESULTS AND DISCUSSION}

Surface alkoxytin complexes metathesize readily with phenols because of their pKa values [13] relative to the tert-butanol product ( $c a$. 10 and 18, respectively). Ligand metathesis reactions were carried out on an ITO-coated aluminum electrode-equipped QCM, and surface coatings and complex stoichiometries were calculated [12,14] (table I). 
Table I. Loading of surface complexes measured by QCM

\begin{tabular}{cc} 
Species & Surface Loading $\left(\mathbf{n m o l} / \mathbf{c m}^{\mathbf{2}}\right)$ \\
\hline ITO surface OH content & 0.17 \\
4b & 0.18 \\
4c & 0.19 \\
4d & 0.17
\end{tabular}

The work function $(\phi)$ of a freshly prepared sample of untreated ITO was measured as a baseline with an accuracy of $\pm 0.2 \mathrm{eV}$. The work functions of 2-modified and then 4a-dmodified surfaces were measured using the same gold and untreated ITO standards. Even in the absence of dielectric constants for surface monolayer complexes, it is possible to calculate relative complex dipole moment normal component values $\left(\mu_{\mathrm{z}(\mathbf{4})}\right)$; for $\mathbf{4} \mathbf{b}-\mathbf{d} \mu_{\mathrm{z}(\mathbf{4})}=1.67,2.60$ and $0.66 \mathrm{D}$, respectively [12]. It is noteworthy that a good correlation exists between $\Delta \phi$ and $\mu_{\mathrm{z}(4)}$ and, even more significantly, with the total dipole (z- component) per unit area, $\mu_{\mathrm{z}(4)} \times £_{\mathbf{4}}$ (table II), as predicted by the Helmholtz equation [15].

Devices were prepared by evaporation of $\alpha-\mathrm{NPD}, \mathrm{Alq}_{3}$ and Al successively onto $\mathbf{4 b} \mathbf{b}-\mathbf{d}$, and

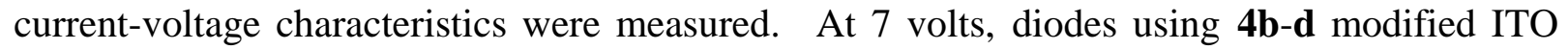
showed an increase in current density of 133-fold, 2100-fold and 18-fold, respectively, vs. untreated ITO. Thus our ITO surface modification procedure allows for controlled, quantitative adjustment of electrode work function and, as well, control of the resulting organic optoelectronic device behavior.

Table II. Gas-phase dipole moments for parent phenols (3), $\Delta \phi$ for surface phenoxide complexes (4), calculated complex dipole moments for 4 normal to the ITO surface $\left(\mu_{\mathrm{z}(4))}\right)$, and dipole moments normal to the ITO surface $\mathrm{x}$ surface complex loading $\left(\mu_{\mathrm{z}(4)} \mathrm{x} £_{4}\right)$.

\begin{tabular}{ccccc} 
Parent Phenol & $\Delta \phi \mathbf{( e V}^{\mathbf{a}}$ & $\left.\mu_{\mathbf{z}(\mathbf{p h e n o l})} \mathbf{( D )}\right)^{\mathbf{b}}$ & $\mu_{\mathbf{z}(\mathbf{4})}(\mathbf{D})^{\mathbf{c}}$ & $\mu_{\mathbf{Z}(\mathbf{4})} \mathbf{x} \mathbf{E}_{\mathbf{4}} \mathbf{d}^{\mathbf{d}}$ \\
\hline phenol (3a) & 0.59 & -0.44 & $\mathrm{e}$ & $\mathrm{e}$ \\
p-fluorophenol (3b) & 1.10 & 1.20 & 1.67 & 0.301 \\
4-(trifluoromethyl)phenol (3c) & 1.48 & 3.06 & 2.60 & 0.416 \\
2,6-difluorophenol (3d) & 0.47 & -1.85 & 0.66 & 0.132
\end{tabular}

Current density-voltage curves were determined for simple hole-only devices (see figure 1 ). When the log of the current density at fixed voltage (7V) for $\mathbf{4 b}$-d-modified surfaces, as well as blank ITO, was plotted against relative work function changes vs. blank ITO, an almost linear relationship was found (see figure 2). This suggests that the hole injection barrier results primarily from the energy mismatch between ITO and NPD at their interface, according to a thermionic emission model [16]. Increasing the ITO work function by systematically changing the structure of surface derivatives decreases this energy barrier. A simple OLED device based on $\mathbf{4} \mathbf{c}$ was built and, as expected, was significantly brighter than the control using unmodified ITO (see figure 3). 


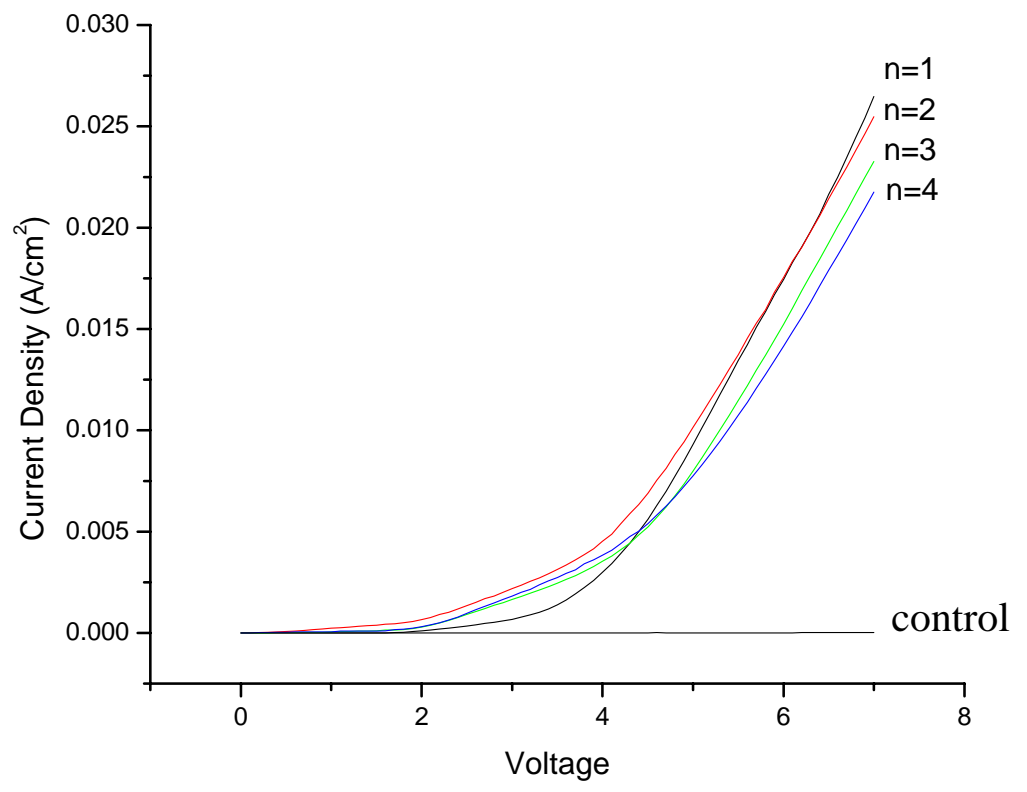

Figure 1. J-V curves for a 4c-based simple hole-only device compared with a control device based on untreated ITO.
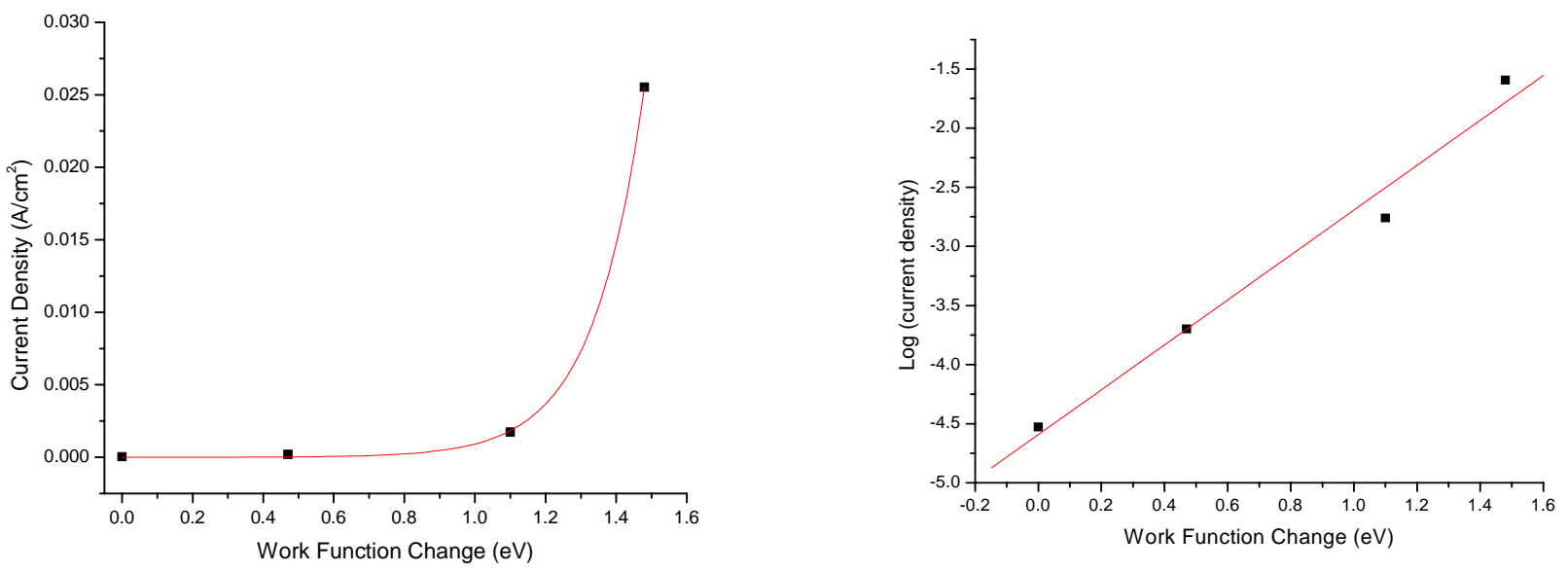

Figure 2. Correlations between work function changes $(\mathrm{eV})$ and current density or log of current density for devices made using $\mathbf{4 b}$-d or untreated ITO. 


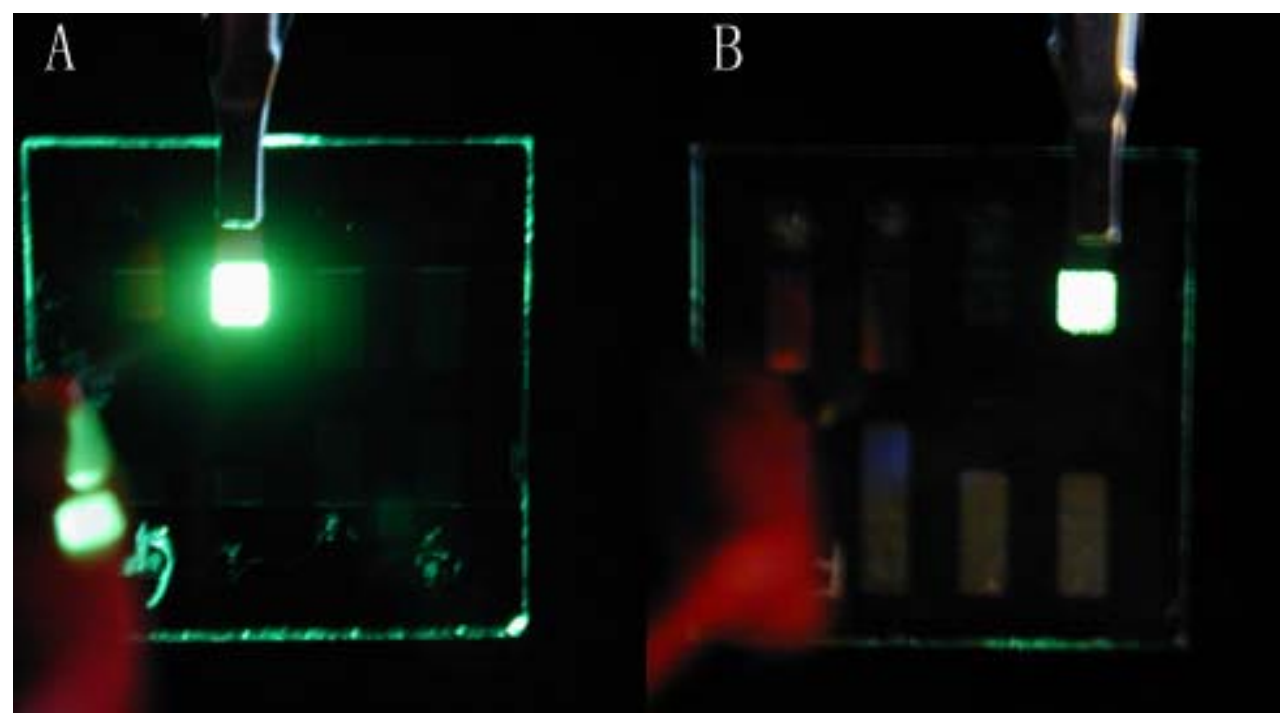

Figure 3. Images of an OLED device (at 15V) (A) based on 4c, and (B) based on untreated ITO.

\section{CONCLUSIONS}

We have shown that we can control the work function of ITO systematically and quantitatively by surface complex structural modification. We have further shown that such modification, arising from simple ligand metathesis schemes, translates predictably into control of resulting device behavior.

\section{ACKNOWLEDGEMENTS}

The authors acknowledge support for this work provided by the National Science Foundation and by the CRG Corporation, San Diego, CA. They also acknowledge Prof. Robert A. Pascal for calculation of gas-phase phenol dipole moments and phenol acidity data, and Professor Antoine Kahn and Mr. Calvin K. Chan for advice in the design and construction of the Kelvin probe.

\section{REFERENCES}

(1) Nüesch, F.; Forsythe, E. W.; Le, Q. T.; Gao, Y.; Rothberg, L. J. J. Appl. Phys. 2000, 87, 7973

(2) Sugiyama, K.; Ishii, H.; Ouchi, Y.; Seki, K. J. Appl. Phys. 2000, 87, 295 
(3) Steuber, F.; Staudigel, J.; Stössel, M.; Simmerer, J.; Winnacker, A. Appl. Phys. Lett. 1999, 74, 3558

(4) Choi, M. W.; Cho, K.; Sung, C.; Yang, J.; Noh, Y. Y. M.; Choi, J. C.; Jeong, K. J. Vac. Sci. Technol. B 2004, 22, 758

(5) Tang, J. X.; Li, Y. Q.; Zheng, L. R.; Hung, L. S. J. Appl. Phys. 2004, 95, 4397

(6) Ke, L.; Kumar, R. S.; Zhang, K.; Chua, S. J.; Wee, A. T. S. Synth. Met. 2004, 140, 295

(7) Ishii, H.; Sugiyama, K.; Ito, E.; Seki, K. Adv. Mater. 1999, 11, 605

(8) Ito, E.; Oji, H.; Furuta, M.; Ishii, H.; Oichi, K.; Ouchi, Y.; Seki, K. Synth. Met. 1999, 101, 654

(9) Milliron, D. J.; Hill, I. G.; Shen, C.; Kahn, A.; Schwartz, J. J. Appl. Phys. 2000, 87, 572

(10) Span, A. R.; Bruner, E. L.; Bernasek, S. L.; Schwartz, J. Langmuir 2001, 17, 948

(11) Bruner, E. L.; Koch, N.; Span, A. R.; Bernasek, S. L.; Kahn, A.; Schwartz, J. J. Am. Chem. Soc. 2002, 124, 3192

(12) Guo, J.; Koch, N.; Schwartz, J.; Bernasek, S. L. J. Phys. Chem. B 2005, 109, 3966

(13) Carey, F. A. Organic Chemistry; 4th ed.; McGraw Hill Higher Education: Boston, 2000.

(14) Sauerbrey, G. Z. Phys. 1959, 155, 206

(15) Christmann, K. Introduction to Surface Physical Chemistry; Springer-Verlag: New York, 1991

(16) Khodabakhsh, S.; Poplavskyy, D.; Heutz, S.; Nelson, J.; Bradley, D. D. C.; Murata, H.; Jones, T. S. Adv. Funct. Mater. 2004, 14, 1205 